\title{
Exposure of Adolescent Rats to Oral Methylphenidate: Preferential Effects on Extracellular Norepinephrine and Absence of Sensitization and Cross-Sensitization to Methamphetamine
}

\author{
Ronald Kuczenski and David S. Segal \\ Department of Psychiatry, School of Medicine, University of California, San Diego, La Jolla, California 92093
}

\begin{abstract}
Methylphenidate (MP) (ritalin) is widely used in the treatment of children and adolescents with attention deficit hyperactivity disorder, but little is known about therapeutic mechanisms or about possible consequences of long-term exposure. To more closely simulate the clinical use of the drug, we orally administered MP to adolescent rats during the dark-active phase of the circadian cycle at doses $(0.75-3.0 \mathrm{mg} / \mathrm{kg})$ below threshold for locomotor activation. We found that doses in this range increased extracellular norepinephrine in hippocampus without affecting dopamine in nucleus accumbens. These results suggest that norepinephrine systems may play an important role in the therapeutic action of this drug. To examine one potential consequence of long-term exposure to MP, i.e., the development of locomotor sensitization, an adaptational change that has been implicated in drug abuse liability, animals received three daily oral administrations of these doses of MP for up to
\end{abstract}

Most evidence supports the use of amphetamine-like stimulants, particularly methylphenidate (MP), as the best available pharmacotherapy in the treatment of children with attention deficit hyperactivity disorder (ADHD) (Safer and Allen, 1989; Garland, 1998; Wigal et al., 1999; Challman and Lipsky, 2000; Biederman et al., 2000). Furthermore, ADHD symptoms continue into adulthood in as many as $60 \%$ of these children, and continued stimulant therapy remains the most effective treatment (Taylor and Russo, 2001). Yet little is known about mechanisms contributing to stimulant therapeutic efficacy or about possible enduring neuroadaptational consequences of this long-term drug exposure (Safer and Allen, 1989; National Institutes of Health Consensus Development Conference Statement, 2000; Greenhill, 2001). In this regard, the persistent effects of repeated exposure to low doses of stimulants in both animals (Robinson and Becker, 1986; Segal and Kuczenski, 1994; Vanderschuren and Kalivas, 2000) and humans (Sax and Strakowski, 1998; Strakowski and Sax, 1998; Strakowski et al., 2001) have raised the possibility of subsequent drug abuse as one consequence of long-term adolescent stimulant treatment (Schenk and Davidson, 1998; Laviola et al., 1999; Brandon et al., 2001).

MP promotes many of the neurochemical effects typically as-

Received Jan. 31, 2002; revised May 16, 2002; accepted May 21, 2002.

This work was supported in part by Public Health Service Grant DA-01568, the Department of Veterans Affairs VISN22 Mental Illness Research Education and Clinical Center, and the University of California San Diego Academic Senate. We thank Skipp McCunney and Jason Kappes for their excellent technical assistance.

Correspondence should be addressed to Dr. Ronald Kuczenski, Department of Psychiatry (0603), University of California San Diego School of Medicine, 9500 Gilman Drive, La Jolla, CA 92093. E-mail: rkuczenski@ucsd.edu.

Copyright (C) 2002 Society for Neuroscience $0270-6474 / 02 / 227264-08 \$ 15.00 / 0$
4 weeks through adolescence. The animals were then challenged with methamphetamine $(0.5 \mathrm{mg} / \mathrm{kg})$. We found that the behavioral response to MP did not change during the course of chronic treatment and that MP-pretreated animals did not exhibit a sensitized locomotor response to the methamphetamine challenge. We propose that, to the extent that this treatment protocol more closely reflects clinical exposure patterns, the relative insensitivity of accumbens dopamine to the acute administration of these MP doses, and the corresponding absence of evidence for the development of locomotor sensitization, supports one clinical view that there is little abuse liability associated with low dose, long-term MP treatment.

Key words: amphetamine; methamphetamine; methylphenidate; chronic; dopamine; norepinephrine; attention deficit; adolescent

sociated with other psychomotor stimulants, including dosedependent increases in extracellular dopamine (Kuczenski and Segal, 1997, 2001; Gerasimov et al., 2000) and norepinephrine (Kuczenski and Segal, 1997, 2001), both of which may be implicated in stimulant therapeutic actions (Biederman and Spencer, 1999; Wigal et al., 1999; Arnsten, 2001; Solanto et al., 2001). In addition, some evidence indicates that repeated administration of MP can result in the development of locomotor sensitization, a response alteration that has been implicated in drug abuse liability (Robinson and Berridge, 1993). However, the relevance of these data within the context of stimulant exposure in the treatment of children with ADHD is ambiguous because previous preclinical studies of MP have not always considered the variety of factors that can affect the resultant effect profiles. For one, dose and route of administration are important because the features of the behavioral and neurochemical responses to these drugs depend on the rate of rise of drug concentration and the maximum concentration achieved. In this regard, the clinical use of MP typically involves oral administration of relatively low doses, whereas most preclinical studies of this drug have used much higher doses, generally administered intraperitoneally, leading to peak plasma levels of the drug much higher than typically achieved under therapeutic conditions (see Methods for more detailed discussion). In addition, most preclinical studies of MP used adult rats, and, with few exceptions (Gaytan et al., 1997b, 2000), have been conducted during the light phase, the period of normal inactivity in the rat, which is $180^{\circ}$ out of phase with clinical treatment. Other potentially critical factors include the duration and the pattern of drug exposure, and all these factors have been shown to significantly influence acute and chronic 
stimulant effects (Robinson and Becker, 1986; Segal and Kuczenski, 1994; Laviola et al., 1999; Gaytan et al., 1999, 2000).

To more closely simulate the clinical use of MP, we used low doses of oral MP administered to young rats during the darkactive phase of the circadian cycle. The doses were selected on the basis of pharmacokinetic modeling to achieve peak plasma levels near the clinical range. We compared the nucleus accumbens dopamine and hippocampus norepinephrine responses to determine how these transmitters might be affected by low oral doses of the drug. We also assessed possible changes in behavioral response associated with repeated exposure under these more clinically relevant conditions: oral MP, administered three times each day during the dark-active phase, initiated in adolescent animals and continued (for 4 weeks) into early adulthood. Finally, because a sensitized behavioral response to later stimulant challenge may be expressed in the absence of changes during repeated treatment, we also determined whether locomotor sensitization in response to methamphetamine (METH) challenge occurred $10 \mathrm{~d}$ after discontinuation of the chronic MP administration.

\section{MATERIALS AND METHODS}

Subjects. Male Sprague Dawley rats, 28-d-old and weighing 110-130 gm ( 1 week after weaning), were obtained from Simonsen Labs (Gilroy, CA). Before treatment, animals were housed in groups of three in wire mesh cages, with ad libitum access to food and water, in a temperature- and humidity-controlled room, maintained on a reversed $12 \mathrm{hr}$ dark (7:00 A.M. to 7:00 P.M.), 12 hr light cycle. All studies adhered to animal welfare guidelines (Principles of Laboratory Animal Care, National Institutes of Health Publication \#85-23).

Drugs. Methylphenidate $\mathrm{HCl}$ (National Institute on Drug Abuse, Rockville, MD) was dissolved in saline and administered in a volume of $2 \mathrm{ml} / \mathrm{kg}$ by gavage. Methamphetamine $\mathrm{HCl}$ (Sigma, St. Louis, MO) was dissolved in saline and administered subcutaneously. Doses represent the free base.

Apparatus. Behavior was monitored in custom-designed activity chambers (Segal and Kuczenski, 1987). Briefly, each of the chambers was located in a sound-attenuated cabinet maintained on a $12 \mathrm{hr}$ reversed light/dark cycle with constant temperature $\left(24^{\circ} \mathrm{C}\right)$ and humidity $(55 \pm$ $5 \%)$. Each chamber consisted of two compartments: an activity-exploratory compartment $(30 \times 20 \times 38 \mathrm{~cm})$ and a smaller "home" compartment $(14 \times 14 \times 10 \mathrm{~cm})$ in which food and water were available ad libitum. Movements of the animal between quadrants within the activityexploratory compartment (i.e., crossovers) and rearings against the wall, as well as eating and drinking and other vertical and horizontal movements (e.g., intercompartment crossings) were monitored continuously by computer. In addition to the computer-monitored behaviors, representative animals ( $n$ values $=5-7$ per group) were simultaneously videotaped for $60 \mathrm{sec}$ at successive 5 min intervals throughout the response to further assess qualitative features of the behavior. After each sampling interval, the possible appearance of responses or behavior patterns, undetectable by our automated methods, were noted by the rater, who was unaware of treatment conditions.

Microdialysis. For dialysis studies, animals were stereotaxically implanted with guide cannulas using procedures previously described in detail (Kuczenski and Segal, 1989). Guide cannulas extended $2.6 \mathrm{~mm}$ below the surface of the skull and were aimed at the dorsal hippocampus ( $3.8 \mathrm{~mm}$ posterior to bregma, $2.0 \mathrm{~mm}$ lateral, and $4.0 \mathrm{~mm}$ below dura) and the nucleus accumbens $(2.2 \mathrm{~mm}$ anterior, $1.5 \mathrm{~mm}$ lateral, $7.8 \mathrm{~mm}$ below dura). After surgery, animals were housed individually and were allowed 1 week to recover before receiving any treatment.

On the day before the experimental day (3:00-4:00 P.M.), each rat was placed in the dialysis chamber, and the dialysis probes were inserted to allow for acclimation to the test environment and for adequate equilibration of the dialysis probes. The dialysis chambers were essentially identical to the behavioral chambers described above, with the exception that the "home" compartment was removed to prevent interferences introduced by the dialysis methodology. Concentric microdialysis probes were constructed of Spectra/Por hollow fiber (molecular weight cutoff 6000 , outer diameter $250 \mu \mathrm{m}$ ) according to the method of Robinson and Whishaw (1988) with modifications (Kuczenski and Segal, 1989). The length of the active probe membrane was $2 \mathrm{~mm}$ for hippocampus and 1.5 $\mathrm{mm}$ for nucleus accumbens. Probes were perfused with artificial CSF (in mM: $147 \mathrm{NaCl}, 1.2 \mathrm{CaCl}_{2}, 0.9 \mathrm{MgCl}_{2}$, and $4.0 \mathrm{KCl}$ ) delivered by a microinfusion pump $(1.5 \mu \mathrm{l} / \mathrm{min})$ via $50 \mathrm{~cm}$ of Micro-line ethyl vinyl acetate tubing connected to a fluid swivel. Dialysate was collected through glass capillary tubing into vials containing $20 \mu \mathrm{l}$ of $25 \%$ methanol and $0.2 \mathrm{M}$ sodium citrate, $\mathrm{pH} 3.8$. Under these conditions, dialysate norepinephrine, dopamine, and serotonin and metabolites were stable throughout the collection and analysis interval. Samples were collected outside the experimental chamber to avoid disturbing the animal. Individual probe recoveries were estimated by sampling a standard dopamine solution in vitro. Preliminary studies indicated that individual probe recoveries for dopamine and norepinephrine were similar. At the end of the experiment, each animal was perfused with formalin for histological verification of probe placements.

Dialysate samples were collected every $20 \mathrm{~min}$. Nucleus accumbens samples were assayed for dopamine, 3,4-dihydroxyphenylacetic acid, homovanillic acid, 3-methoxytyramine 5-hydroxyindoleacetic acid, and serotonin. In all experiments, solutions of standards revealed a clean separation between 3-methoxytyramine and serotonin. The HPLC-EC consisted of a $100 \times 4.6 \mathrm{~mm}$ ODS-C18 $3 \mu \mathrm{m}$ column (Regis) maintained at $40^{\circ} \mathrm{C}$. Mobile phase $(0.05 \mathrm{M}$ citric acid, $7 \%$ methanol, $0.1 \mathrm{~mm}$ $\mathrm{Na}_{2}$ EDTA, and $0.2 \mathrm{~mm}$ octane sulfonate adjusted to $\mathrm{pH} 4.0-4.5$ ) was delivered at $0.6-0.8 \mathrm{ml} / \mathrm{min}$ by a Waters model 510 pump. In hippocampus samples, norepinephrine was separated using a similar mobile phase containing $4 \%$ methanol and $1.5 \mathrm{~mm}$ octane sulfonate. Amines were detected with a Waters 460 detector with a glassy carbon electrode maintained at $+0.65 \mathrm{~V}$ relative to a $\mathrm{Ag}-\mathrm{AgCl}$ reference electrode. Concentrations were estimated from peak heights using a Waters Maxima 820 data station. Substances in the dialysates were corrected for individual probe recoveries to account for this source of variability, and, although the exact relationship between dialysate concentration and actual extracellular transmitter content is not clear, values are presented as dialysate concentration to allow for meaningful comparisons to other data in the literature.

Methods. Ten days after arrival (38-d-old, 140-160 gm), and $3 \mathrm{~d}$ before initiation of drug treatment, animals were placed in individual experimental chambers where they remained for the duration of the experiment. For all experiments, $n$ values $=6-10 /$ group. To facilitate habituation to the chambers and procedures, animals were handled and administered saline two times each day. During the remainder of the day and night, animals were not disturbed, and their behavior was continuously monitored. By initiation of drug treatment, animals exhibited a typical circadian pattern of behavioral activity, time spent in the home chamber, and ingestion, corresponding to the reversed light/dark cycle, and the dark phase activity of saline-treated animals remained stable throughout the duration of the experiment (data not shown).

Rationale for selection of doses. The clinical use of MP in the treatment of ADHD typically involves oral administration of doses $(0.25-1.0 \mathrm{mg} /$ $\mathrm{kg}$ ), which result in peak plasma levels of MP in the $8-40 \mathrm{ng} / \mathrm{ml}$ range, with $\sim 10 \mathrm{ng} / \mathrm{ml}$ typically considered optimal (Swanson et al., 1999; Swanson and Volkow, 2002). Although our previous studies (Kuczenski and Segal, 2001) used doses of MP which, on a milligram per kilogram basis, are equivalent to therapeutic doses, they did not take into account other, potentially critical pharmacokinetic factors. For one, we had used the intraperitoneal route of MP administration, which results in a faster rate of drug accumulation and higher peak drug concentrations than does oral administration of comparable doses. Thus, the response to oral administration is effectively equivalent to a lower intraperitoneal dose (Gerasimov et al., 2000). Second, although extrapolation on a milligram per kilogram basis provides a crude estimate of equivalent doses, it does not take into account species differences in gastric absorption, volume of drug distribution, drug metabolism, and excretion rates (Wargin et al., 1983; Patrick et al., 1984; Mordenti, 1986; Benet et al., 1990). Therefore, the selection of appropriate doses in rats to achieve a more accurate representation of the clinical range of plasma levels cannot rely simply on equating doses on a milligram per kilogram basis.

Although the few pharmacokinetic data in the literature regarding oral MP in rats are not entirely consistent (Patrick et al., 1984), two reports suggest a reasonable approximation of plasma levels equivalent to therapeutic conditions. In the most systematic study, Aoyama et al. (1990) examined several MP doses and reported nonlinearity that was particularly evident in the lower range of the dose-response curve, with peak plasma levels at $15 \mathrm{~min}$ of $2.1 \mathrm{ng} / \mathrm{ml}$ after $0.5 \mathrm{mg} / \mathrm{kg} \mathrm{MP}, 36 \mathrm{ng} / \mathrm{ml}$ after $2.0 \mathrm{mg} / \mathrm{kg}$, and $62 \mathrm{ng} / \mathrm{ml}$ after $3.5 \mathrm{mg} / \mathrm{kg}$. Based on these results, doses between $0.5 \mathrm{mg} / \mathrm{kg}$ and $3.5 \mathrm{mg} / \mathrm{kg}$ should promote peak plasma MP 
concentrations within the typical clinical range $(8-40 \mathrm{ng} / \mathrm{ml})$. The findings of Wargin et al. (1983) are consistent with these estimates. Furthermore, our own pharmacokinetic data, obtained in collaboration with Dr. John Cashman (Human Bio Molecular Institute, San Diego, CA), are similar to the results of both Aoyama et al. (1990) and Wargin et al. (1983). Plasma levels of MP were assessed after dichloromethaneisopropanol extraction in the presence of deuterated internal standards (Doerge et al., 2000) using a Hewlett Packard 1100 LC/MSD single quadrupole mass spectrometer. We found plasma concentrations of $9.3 \pm$ $2.3 \mathrm{ng} / \mathrm{ml}$ during the $5-15 \mathrm{~min}$ after oral administration of $1.0 \mathrm{mg} / \mathrm{kg}$ to our adolescent rats $(n=8)$. Based on all these results, we estimate that oral administration of $0.75 \mathrm{mg} / \mathrm{kg}$ would yield peak plasma levels between 2 and $9 \mathrm{ng} / \mathrm{ml}$, corresponding to the lower limit of typical clinical values, whereas a dose of $3.0 \mathrm{mg} / \mathrm{kg}$ would promote peak plasma concentrations between 30 and $60 \mathrm{ng} / \mathrm{ml}$, corresponding to the upper extreme of the clinical range. We included both these, as well as intermediate doses in our studies, based on the assumption that analyses over the full range of clinically relevant doses should provide a more complete and more interpretable characterization of the spectrum of effects associated with clinical treatment than would be possible with a single dose.

Chronic MP treatment. Because MP has a shorter half-life in rats $(\sim 1$ hr) (Patrick et al., 1984; Aoyama et al., 1990; Thai et al., 1999) compared with humans (2-3 hr) (Patrick and Markowitz, 1997), it has been suggested that this difference in duration of exposure can be best corrected by increasing the intraperitoneal dose (Gerasimov et al., 2000). However, as previously discussed, considerable evidence shows that the absolute peak level and the rate at which it is achieved, as well as duration of exposure, are both important factors in determining the acute and chronic effects of stimulants. Therefore, in our chronic studies we used three daily oral administrations of the drug, spaced at $3 \mathrm{hr}$ intervals, as a more appropriate means of adjusting the duration of daily drug exposure. MP or saline administration was initiated in 41-d-old animals (experimental day 1), and throughout the chronic MP treatment, animals remained in the activity chambers while their behavior was continuously monitored. Chronic MP exposure was maintained $5 \mathrm{~d}$ /week over a 4 week period, with the final treatment occurring on day 26 . No drug was administered on weekend days [corresponding to the drug-free periods frequently associated with clinical treatment (Committee on Children with Disabilities, 1996)], at which time all animals were handled during normal servicing of the experimental chambers.

It has been argued that a drug-free interval may be required to optimize the expression of a sensitized locomotor response (Kalivas and Duffy, 1993a,b; Paulson and Robinson, 1995). Therefore, the animals remained drug-free for $10 \mathrm{~d}$ before stimulant challenge. For the $5 \mathrm{~d}$ after cessation of MP administration (days 27-32), all animals continued to receive a single daily saline administration by gavage. Then, in preparation for subsequent subcutaneous METH challenge, on days 33-36, animals received a single daily subcutaneous saline injection, and on day 37 , animals were challenged with $0.5 \mathrm{mg} / \mathrm{kg}$ METH. On the subsequent $16 \mathrm{~d}$ (through day 53), all animals continued to receive single daily subcutaneous injections of $0.5 \mathrm{mg} / \mathrm{kg}$ METH.

Data analysis. Behavioral and neurochemical data were statistically analyzed using repeated measures ANOVA and $t$ tests with Bonferroni corrections for specific group and time comparisons.

\section{RESULTS}

\section{Neurotransmitter responses to acute oral MP administration}

We had previously reported a dose-dependent increase in extracellular norepinephrine concentrations in hippocampus after acute intraperitoneal administration of low doses of MP, whereas nucleus accumbens dopamine was relatively less affected (Kuczenski and Segal, 2001). To determine whether this preferential effect on norepinephrine responsivity was evident after oral administration of low doses of MP to adolescent rats during the active-dark phase of the circadian cycle, we assessed norepinephrine and dopamine in these same regions in response to 1.0, 2.5, and $5.0 \mathrm{mg} / \mathrm{kg}$ MP. The 1.0 and $2.5 \mathrm{mg} / \mathrm{kg}$ doses were selected to achieve peak plasma MP concentrations within the clinically relevant range, whereas the $5.0 \mathrm{mg} / \mathrm{kg}$ dose was estimated to produce peak plasma levels exceeding this range. Consistent with

\section{Hippocampus Norepinephrine Response to Oral Methylphenidate}

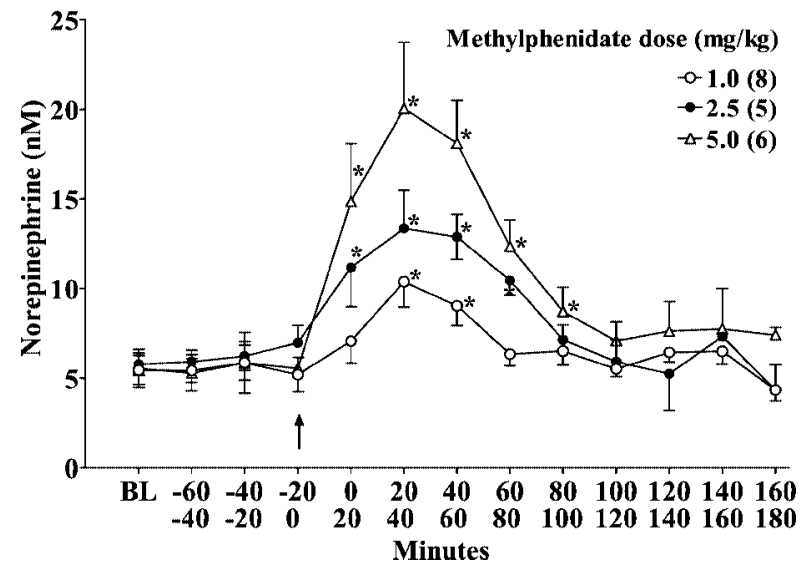

Figure 1. Dose-response and temporal profiles of the hippocampus extracellular norepinephrine response to an acute oral administration of methylphenidate $(1.0,2.5,5.0 \mathrm{mg} / \mathrm{kg})$, presented as absolute values corrected for probe recovery. Values represent the mean \pm SEM. BL values are the median of the three samples collected immediately before drug administration. ${ }^{*} p<0.05$ compared with the sample collected immediately before drug administration.

\section{Nucleus Accumbens Dopamine Response to Oral Methylphenidate}

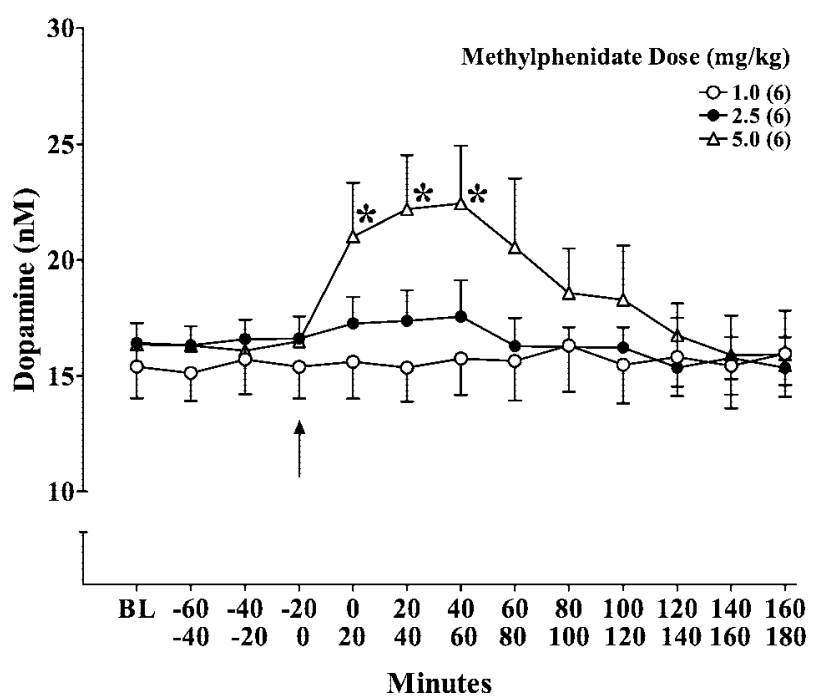

Figure 2. Dose-response and temporal profile of the nucleus accumbens extracellular dopamine response to an acute oral administration of methylphenidate $(1.0,2.5,5.0 \mathrm{mg} / \mathrm{kg})$, presented as absolute values corrected for probe recovery. Values represent the mean \pm SEM. BL values are the median of the three samples collected immediately before drug administration. * $p<0.05$ compared with the sample collected immediately before drug administration.

a previous report (Gerasimov et al., 2000), only the $5.0 \mathrm{mg} / \mathrm{kg}$ dose produced a significant increase in locomotor activity [Crossovers (10-60 min): saline, $39 \pm 8 ; 5.0 \mathrm{mg} / \mathrm{kg} \mathrm{MP}, 68 \pm 9 ; t=2.27$, $p<0.05]$.

The hippocampus norepinephrine and nucleus accumbens dopamine responses are summarized in Figures 1 and 2, respectively. MP promoted a dose-dependent increase in both norepinephrine and dopamine, but there was a preferential norepinephrine response that was particularly pronounced at the MP doses in the 


\section{Locomotor Response to Oral MP Administration}

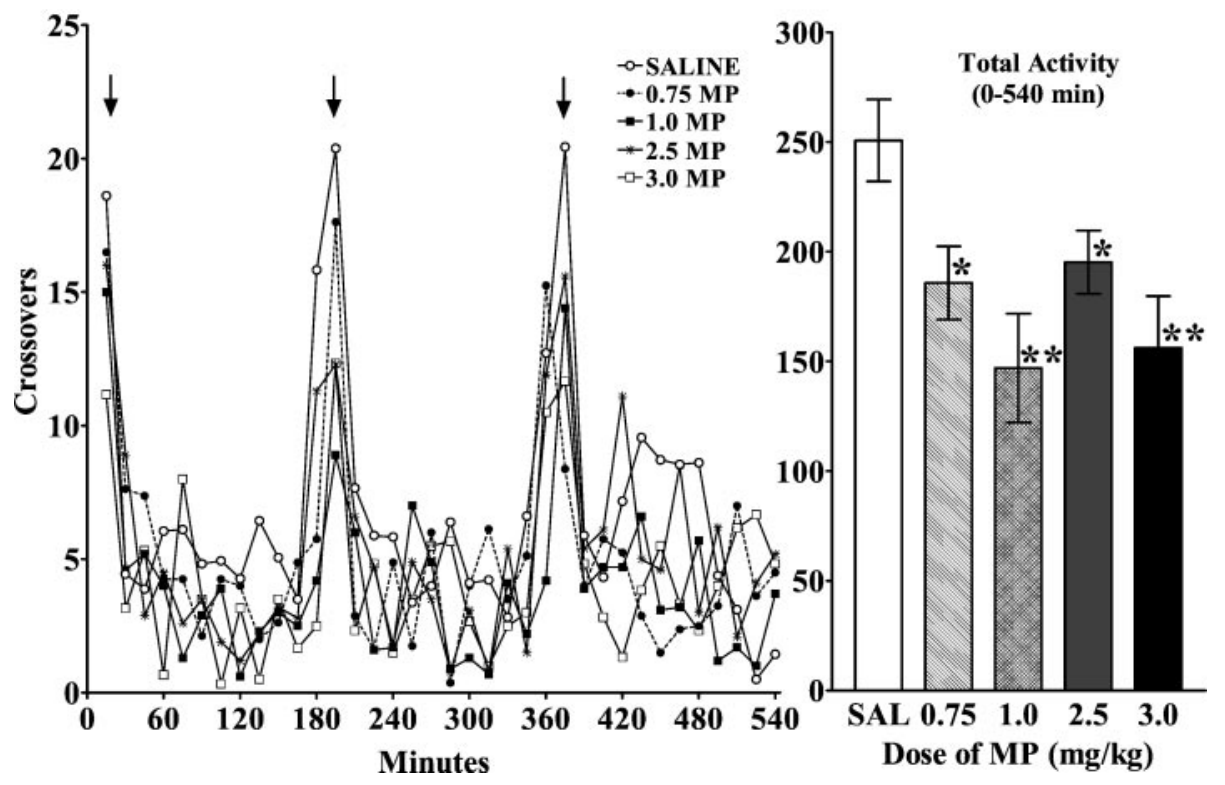

Figure 3. Effects of oral MP administration on locomotor activity of adolescent rats during the dark (active) phase of the circadian cycle. Left, Temporal pattern of locomotor activity in response to three successive oral MP administrations (arrows). Animals received three administrations of SAL or one of the indicated doses of MP at $3 \mathrm{hr}$ intervals. Values represent the mean \pm SEM. Right, The cumulated locomotor response to three successive oral administrations of MP or SAL. Values represent the cumulated activity (mean \pm SEM) during the $9 \mathrm{hr}$ after the first administration. Data were obtained from two separate experiments, and the control groups, which did not differ significantly in their response to saline administration, were combined for subsequent statistical analysis. ANOVA revealed a significant effect of drug treatment during the $9 \mathrm{hr}$ interval $\left(F_{(4,47)}=4.88 ; p<\right.$ $0.0022)\left({ }^{*} p<0.05 ; * * p<0.01\right.$ compared with saline) but no significant effect of drug treatment during the initial $150 \mathrm{~min}$ interval $\left(F_{(4,47)}=2.32\right.$; $p=0.07)$.

clinical range. Thus, the two lower MP doses significantly increased norepinephrine levels (Fig. 1) without a significant effect on dopamine (Fig. 2). We did observe a significant increase in dopamine $(\sim 40 \%)$ in response to the highest dose of oral MP $(5 \mathrm{mg} / \mathrm{kg})$ (Fig. 2), consistent with the recent results of Gerasimov et al. (2000).

\section{Behavioral response to acute oral MP}

The doses of MP which, when administered orally, preferentially increased extracellular norepinephrine, tended to decrease locomotion $\left(F_{(4,47)}=2.32 ; p=0.07\right)$ (Fig. 3). This trend toward decreased locomotor behavior achieved statistical significance for activity, cumulated for the three $3 \mathrm{hr}$ intervals after the three successive MP administrations through the day $\left(F_{(4,47)}=4.88\right.$; $p=0.002$ ) (Fig. 3). Videotaped observations revealed that the behavior of the MP-treated animals was otherwise not obviously distinguishable from saline-treated control animals.

\section{Behavioral responsivity during and after chronic oral MP}

Animals that received three daily oral administrations of saline or MP $(0.75$ or $3.0 \mathrm{mg} / \mathrm{kg})$ for 4 weeks did not exhibit tolerance or sensitization in response to the drug during the course of the treatment [crossings ( $0-540 \mathrm{~min})$, first day vs last day; dose: $F_{(2,18)}=2.49, p=0.1$; days of treatment: $F_{(1,18)}=2.89, p=0.1$; dose $\times$ days: $\left.F_{(2,18)}=1.0, p=0.4\right]$.

Because an altered response to later stimulant challenge may be expressed in the absence of changes during chronic treatment, we also determined the effect of this 4 week chronic MP pretreatment on the response to a METH challenge. On the tenth day after the last MP treatment, all animals received METH (0.5 $\mathrm{mg} / \mathrm{kg}$, s.c.), and their locomotor responses are summarized in Figure 4. There was no evidence for a sensitized locomotor response in the MP-pretreated groups, and, in fact these animals exhibited significantly less locomotion than saline-pretreated controls during the initial intervals after METH administration [crossovers $\left.(0-20 \mathrm{~min}) F_{(2,19)}=5.79, p=0.01\right]$. This observation was replicated in a related study, in which animals received oral MP (1.0 or $2.5 \mathrm{mg} / \mathrm{kg}$ ) three times daily for five successive days. When these adolescent rats were challenged with METH $(0.5$

\section{Locomotor Response To METH (0.5 mg/kg): Day 1}
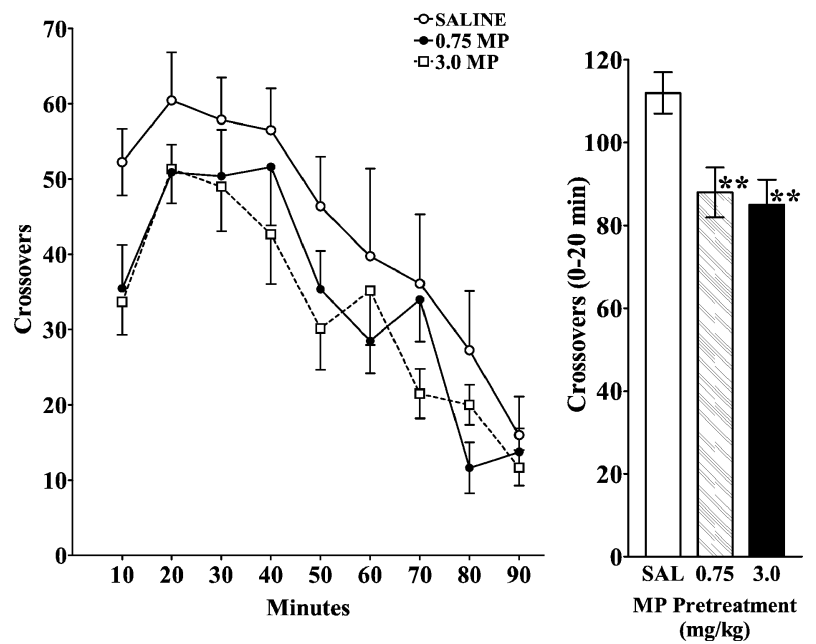

Figure 4. Effects of oral MP pretreatment on the temporal pattern of locomotor activity in response to a subcutaneous METH $(0.5 \mathrm{mg} / \mathrm{kg})$ challenge. Groups of animals received oral saline or MP (0.75 or 3.0 $\mathrm{mg} / \mathrm{kg}$ ) three times daily for 4 weeks. See Materials and Methods for details. Ten days after the last pretreatment administration, animals were challenged with METH $(0.5 \mathrm{mg} / \mathrm{kg})$. Values represent the mean $\pm \mathrm{SEM}$. Bar graphs represent the cumulated response during the initial $20 \mathrm{~min}$ after drug administration. ANOVA revealed a significant effect of pretreatment $\left(F_{(2,19)}=5.79 ; p=0.01\right)$. ${ }^{* *} p<0.01$ compared with salinepretreated group.

$\mathrm{mg} / \mathrm{kg}$ ) on the tenth day after the last pretreatment, the MPpretreated groups exhibited a significantly decreased locomotor response (crossovers, 0-180 min: saline, $412 \pm 28 ; 1.0 \mathrm{mg} / \mathrm{kg}$ $\mathrm{MP}, 286 \pm 49 ; 2.5 \mathrm{mg} / \mathrm{kg} \mathrm{MP}, 273 \pm 43$; ANOVA: $F_{(2,27)}=3.46$, $p<0.05)$.

To determine whether the development and/or expression of locomotor sensitization to repeated, intermittent administration of METH would be altered by the oral MP pretreatment, and the animals pretreated with 0.75 or $3.0 \mathrm{mg} / \mathrm{kg} \mathrm{MP}$ for 4 weeks continued to receive single daily injections of $0.5 \mathrm{mg} / \mathrm{kg}$ METH 


\section{Locomotor Response To METH (0.5 mg/kg): Day 17}

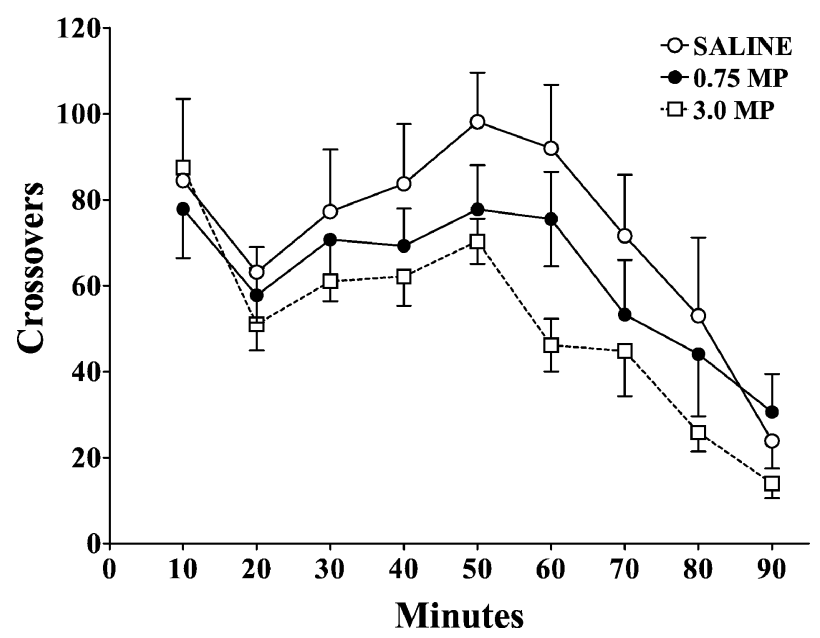

Figure 5. Effects of oral MP pretreatment on the temporal pattern of locomotor activity in response to the 17 th METH $(0.5 \mathrm{mg} / \mathrm{kg})$ administration. Groups of animals received oral saline or MP $(0.75$ or $3.0 \mathrm{mg} / \mathrm{kg})$ three times daily for 4 weeks. See Materials and Methods for details. Ten days after the last pretreatment administration, animals were treated with single daily subcutaneous administration of METH $(0.5 \mathrm{mg} / \mathrm{kg})$. Values represent the mean \pm SEM. ANOVA revealed a significant effect of repeated $\mathrm{METH}$ treatment compared with the response on day 1 (Fig. 4) $\left(F_{(1,19)}=29.64 ; p<0.001\right)$.

for an additional $16 \mathrm{~d}$. The response to the METH treatment on the $17^{\text {th }}$ day is summarized in Figure 5. All groups exhibited a marked sensitization after repeated METH treatment $\left(F_{(1,19)}=\right.$ 29.64; $p<0.001$ ), but there were no significant differences in the responses to the METH challenge as a function of MP pretreatment $\left(F_{(2,19)}=1.59, p=0.2\right.$; interaction: $\left.F_{(2,19)}=0.41, p=0.7\right)$.

\section{DISCUSSION}

In the present series of studies, we characterized the neurochemical and behavioral effects of low doses of MP in adolescent rats under conditions that attempt to approximate the pattern of exposure associated with clinical treatment of ADHD. Under these conditions we found unique characteristics of this drug that differ from the effects of higher doses, and therefore may be relevant to the therapeutic efficacy of the stimulants, and to the potential consequences of their long-term administration.

\section{Neurotransmitter responses}

The present results show that oral administration of low MP doses to adolescent animals during the dark-active phase of the circadian cycle can increase extracellular norepinephrine concentrations in hippocampus without significantly affecting extracellular dopamine in nucleus accumbens. These observations are of potential therapeutic relevance because the doses of MP which produced this preferential effect are estimated to result in plasma (Wargin et al., 1983; Aoyama et al., 1990) and brain (Volkow et al., 1998) levels of the drug within the range typically achieved under clinical conditions (Shaywitz et al., 1982; Wargin et al., 1983; Swanson et al., 1999; Vitiello et al., 2001). Thus, these results indicate that stimulant-induced changes in norepinephrine pathways may be particularly important to the therapeutic efficacy of these drugs. This suggestion is consistent with accumulating evidence that pharmacotherapy involving drugs with relative selectivity toward norepinephrine can be efficacious in the treat- ment of ADHD symptoms (Biederman and Spencer, 1999; Michelson et al., 2001; Scahill et al., 2001; Szabo and Blier, 2001).

A number of studies have also suggested a role for mesolimbic dopamine in the stimulant treatment of ADHD (Salamone et al., 1997; Hollander and Evers, 2001; Sagvolden, 2001; Taylor and Jentsch, 2001). In support of this view, Volkow et al. (2001) recently used positron emission tomography and displacement of $\left[{ }^{11} \mathrm{C}\right]$ raclopride to measure changes in extracellular dopamine after oral administration of MP to an adult volunteer group. Using this approach, they observed a small but significant increase in extracellular dopamine in striatum. Our failure to observe a significant increase in accumbens dopamine (Fig. 2) with doses of the drug that we estimated to be in the clinical range is not necessarily inconsistent with these human data. Those authors used a relatively high dose of MP $(0.8 \mathrm{mg} / \mathrm{kg})$ to achieve peak plasma MP concentrations of $34 \mathrm{ng} / \mathrm{ml}$, at the upper limits of the clinical range. Furthermore, the changes in extracellular dopamine they observed included some individuals with minimal (3\%) dopamine responses, suggesting that even this relatively high dose of MP $(0.8 \mathrm{mg} / \mathrm{kg})$ may be near threshold for the induction of a significant striatal dopamine response. Additional pharmacokinetic studies will be required to determine how the highest dose we used to approximate the clinical range compares to the $0.8 \mathrm{mg} / \mathrm{kg}$ dose in the human study. Nevertheless, our dose-response results suggest that lower, more typical therapeutic doses of MP may be below the threshold for increasing striatal dopamine.

However, a minimal effect of low doses of MP on dopamine in nucleus accumbens does not preclude a more substantial effect in other dopamine projection sites, particularly in prefrontal cortex, which appears to play a particularly important role in processes that have been implicated in ADHD (Hale et al., 2000; Mehta et al., 2000; Moll et al., 2000; Robbins, 2000; Arnsten, 2001). For one, compared with mesostriatal (including accumbens) dopamine, cortical dopamine afferents exhibit a lower density of dopamine transporters (Sesack et al., 1998), which may result in a slower dopamine uptake. In addition, evidence suggests that, as one consequence of the low density of dopamine transporters, extracellular dopamine in cortex may be partially inactivated by uptake into norepinephrine nerve terminals (Tanda et al., 1997; Wayment et al., 2001). In this regard, although we did not examine the effects of oral doses of MP on cortical norepinephrine, we found in our previous examination of the regional norepinephrine responses to stimulants, that hippocampus and prefrontal cortex norepinephrine respond with similar sensitivity to these drugs (Kuczenski and Segal, 1992; Florin et al., 1994). Thus, inhibition of norepinephrine uptake by clinically relevant doses of MP may also contribute to an MP-induced increase in cortical dopamine, and, as a consequence, cortical dopaminergic transmission may be facilitated at doses of the stimulant that do not affect accumbens dopamine. Dopaminergic effects of MP in cortex may be important with regard to therapeutic efficacy because cortical dopamine, like norepinephrine, has been linked to attentional and cognitive functions that may be implicated in ADHD (GoldmanRakic et al., 2000; Robbins, 2000; Arnsten, 2001).

\section{Behavioral responses}

The decrease in behavioral activity that we observed in response to acute oral administration of the lower range $(0.75-3.0 \mathrm{mg} / \mathrm{kg})$ of MP doses contrasts with the increased locomotor response that we found in past studies using intraperitoneal administration of similar MP doses (Kuczenski and Segal, 2001). However, it 
should be noted that higher peak plasma drug levels result from the intraperitoneal route (Patrick et al., 1984), and thus, the correspondingly greater effect on nucleus accumbens dopamine could be sufficient to promote behavioral activation. Therefore, the biphasic pattern of the dose-response with respect to locomotion may reflect the increasing predominance of dopamine activation, relative to norepinephrine, as the dose is increased. It should be emphasized that the low dose MP-induced reduction in locomotor activity was relatively small and only achieved statistical significance when comparisons were made over the $9 \mathrm{hr}$ interval incorporating three successive MP administrations. Nevertheless, the available data further establishes the importance of identifying an appropriate dose range to study mechanisms potentially relevant to stimulant pharmacotherapy. This issue may be particularly germane to the accurate determination of possible consequences of chronic exposure to MP, such as the development of stimulant sensitization, which appears to be critically dependent, at least in part, on the stimulant dosing regimen.

Sensitization processes may be implicated in drug abuse liability (Robinson and Berridge, 1993), and mesolimbic dopamine plays a critical role in stimulant-induced locomotor sensitization (for review, see Robinson and Becker, 1986; Segal and Kuczenski, 1994; White, 1996; Pierce and Kalivas, 1997; White and Kalivas, 1998; Vanderschuren and Kalivas, 2000). Thus, the absence of a significant accumbens dopamine response at the MP doses that we estimate to be clinically relevant may have important consequences for long-term effects. In this regard, few studies have been described that used the low doses typically associated with clinical treatment or that considered the other factors relevant to therapeutic treatment that might significantly influence the longterm effects of MP. In general, the results of the studies that have used doses of MP that, at least on a milligram per kilogram basis are near the clinical range, are contradictory with respect to the induction of locomotor sensitization (McNamara et al., 1993; Gaytan et al., 1997a; Sripada et al., 1998; Brandon et al., 2000; Gaytan et al., 2000; Kuczenski and Segal, 2001), or the consequences of chronic pretreatment on various measures of abuse liability. For example, two recent reports, designed to examine possible abuse liability, characterized persistent behavioral effects of repeated MP exposure in young animals [postnatal days 35-42 (Brandon et al., 2001) or 20-35 (Andersen et al., 2002)] using similar dosing ( $2 \mathrm{mg} / \mathrm{kg}$, i.p.). In one of these studies, Brandon et al. (2001) reported an increase in cocaine self-administration when animals were subsequently tested as young adults; however, Andersen et al. (2002) found a decrease in cocaine reward when animals were tested using a place conditioning paradigm. A variety of explanations might contribute to the inconsistent results, including the use of different methodologies. In addition, although it has been argued that, because of the short half-life of $\mathrm{MP}$ in rats, an intraperitoneal MP dose of $2 \mathrm{mg} / \mathrm{kg}$ may approximate the clinical exposure pattern (Gerasimov et al., 2000), the available data (Patrick et al., 1984; Thai et al., 1999), suggest that doses in this range would yield peak plasma drug concentrations near 150-200 ng/ml, well beyond typical clinical values. It should be noted, however, that although we have suggested multiple administrations of oral doses as a more appropriate means of simulating the duration of daily therapeutic treatment, the relative merits of the various dosing regimens remain to be determined. Nevertheless, our results using multiple oral doses clearly indicate that sensitization of the locomotor response does not develop either to MP during the chronic treatment, or to a METH challenge, perhaps in part because therapeutic doses of
MP may not promote sufficient mesolimbic dopamine activation to initiate those processes required for the induction of sensitization. Because the development of sensitization has been implicated in drug abuse liability, our results would support the conclusions of some clinical studies that there is no increased risk for stimulant abuse associated with ADHD stimulant pharmacotherapy (Biederman et al., 1999; Loney et al., 2002).

In summary, the acute oral administration of MP to adolescent rats using a dosing regimen that attempts to simulate the therapeutic exposure pattern in the treatment of ADHD preferentially increases extracellular norepinephrine compared with nucleus accumbens dopamine, suggesting that norepinephrine systems may play an important role in this action of the stimulants. Furthermore, repeated daily exposure of animals to these doses throughout adolescence and into early adulthood does not lead to the development of locomotor sensitization in response to a subsequent stimulant challenge. We propose that, to the extent that this treatment protocol more closely reflects clinical exposure patterns, our findings of the relative insensitivity of accumbens dopamine to the acute administration of these MP doses, and the absence of evidence for the development of sensitization with repeated MP administration supports one clinical view that there is no abuse liability associated with therapeutic MP treatment.

\section{REFERENCES}

Andersen SL, Arvanitogiannis A, Pliakas AM, LeBlanc C, Carlezon Jr WA (2002) Altered responsiveness to cocaine in rats exposed to methylphenidate during development. Nat Neurosci 5:13-14.

Aoyama T, Kotaki H, Iga T (1990) Dose-dependent kinetics of methylphenidate enantiomers after oral administration of racemic methylphenidate to rats. J Pharmacobiol Dyn 13:647-652.

Arnsten AFT (2001) Dopaminergic and noradrenergic influences on cognitive functions mediated by prefrontal cortex. In: Stimulant drugs and ADHD: basic and clinical neuroscience (Solanto MV, Arnsten AFT, Castellanos FX, eds), pp 185-208. New York: Oxford UP.

Benet LZ, Mitchell JR, Sheiner LB (1990) Pharmacokinetics: the dynamics of drug absorption, distribution, and elimination. In: Goodman and Gilman's The pharmacological basis of therapeutics (Gilman AG, Rall TW, Nies AS, Taylor P, eds), pp 3-32. New York: Pergamon.

Biederman J, Spencer T (1999) Attention-deficit/hyperactivity disorder (ADHD) as a noradrenergic disorder. Biol Psychiatry 46:1234-1242.

Biederman J, Wilens TE, Mick E, Spencer T, Faraone SV (1999) Pharmacotherapy of attention-deficit/hyperactivity disorder reduces risk for substance use disorder. Pediatrics 104:E201-E205.

Biederman J, Mick E, Faraone SV (2000) Age-dependent decline of symptoms of attention deficit hyperactivity disorder: impact of remission definition and symptom type. Am J Psychiatry 157:816-818.

Brandon CL, Marinelli M, Baker LK, White FJ (2000) Adolescent exposure to a low dose of methylphenidate enhances reactivity to cocaine. Soc Neurosci Abstr 26:268.

Brandon CL, Marinelli M, Baker LK, White FJ (2001) Enhanced reactivity and vulnerability to cocaine following methylphenidate treatment in adolescent rats. Neuropsychopharmacology 25:651-661.

Challman TD, Lipsky JJ (2000) Methylphenidate: its pharmacology and uses. Mayo Clin Proc 75:711-721.

Committee on Children with Disabilities (1996) Medication for children with attentional disorders. Pediatrics 98:301-304.

Doerge DR, Fogle CM, Paule MG, McCullagh M, Bajic S (2000) Analysis of methylphenidate and its metabolite ritalinic acid in monkey plasma by liquid chromatagraphy/electrospray ionization mass spectrometry. Rapid Commun Mass Spectrom 14:619-623.

Florin SM, Kuczenski R, Segal DS (1994) Regional extracellular norepinephrine responses to amphetamine and cocaine and effects of clonidine pretreatment. Brain Res 654:53-62.

Garland EJ (1998) Pharmacotherapy of adolescent attention deficit hyperactivity disorder: challenges, choices, caveats. J Psychopharmacol 12:385-395.

Gaytan O, Al-Rahim S, Swann A, Dafny N (1997a) Sensitization to locomotor effects of methylphenidate in the rat. Life Sci 61:PL101-PL107.

Gaytan O, Ghelani D, Martin D, Swann A, Dafny N (1997b) Methylphenidate: diurnal effects on locomotor and stereotypic behavior in the rat. Brain Res 777:1-12.

Gaytan O, Lewis C, Swann A, Dafny N (1999) Diurnal differences in amphetamine sensitization. Eur J Pharmacol 374:1-9.

Gaytan O, Yang P, Swann A, Dafny N (2000) Diurnal differences in sensitization to methylphenidate. Brain Res 864:24-39. 
Gerasimov MR, Franceschi M, Volkow ND, Gifford A, Gatley SJ, Marsteller D, Molina PE, Dewey SL (2000) Comparison between intraperitoneal and oral methylphenidate administration: a microdialysis and locomotor activity study. J Pharmacol Exp Ther 295:51-57.

Goldman-Rakic PS, Muly III EC, Williams GV (2000) D1 receptors in prefrontal cells and circuits. Brain Res Rev 31:295-301.

Greenhill LL (2001) Clinical effects of stimulant medication in attention-deficit/hyperactivity disorder (ADHD). In: Stimulant drugs and ADHD: basic and clinical neuroscience (Solanto MV, Arnsten AFT, Castellanos FX eds), pp 31-71. New York: Oxford UP.

Hale TS, Hariri AR, McCracken JT (2000) Attention-deficit/hyperactivity disorder: perspectives from neuroimaging. Ment Retard Dev Disabil Res Rev 6:214-219.

Hollander E, Evers M (2001) New developments in impulsivity. Lancet 358:949-950.

Kalivas PW, Duffy P (1993a) Time course of extracellular dopamine and behavioral sensitization to cocaine. I. Dopamine axon terminals. J Neurosci 13:266-275.

Kalivas PW, Duffy P (1993b) Time course of extracellular dopamine and behavioral sensitization to cocaine. II. Dopamine perikarya. J Neurosci 13:276-284.

Kuczenski R, Segal DS (1989) Concomitant characterization of behavioral and striatal neurotransmitter response to amphetamine using in vivo microdialysis. J Neurosci 9:2051-2065.

Kuczenski R, Segal DS (1992) Regional norepinephrine response to amphetamine using dialysis: comparison to caudate dopamine. Synapse $11: 164-169$.

Kuczenski R, Segal DS (1997) Effects of methylphenidate on extracellular dopamine, serotonin, and norepinephrine: comparison to amphetamine. J Neurochem 68:2032-2037.

Kuczenski R, Segal DS (2001) Locomotor effects of acute and repeated threshold doses of amphetamine and methylphenidate: relative roles of dopamine and norepinephrine. J Pharmacol Exp Ther 296:876-883.

Laviola G, Adriani W, Livia Terranova M, Gerra G (1999) Psychobiological risk factors for vulnerability to psychostimulants in human adolescents and animal models. Neurosci Biobehav Rev 23:993-1010.

Loney J, Kramer JR, Salisbury H (2002) Medicated versus unmedicated ADHD children: adult involvement with legal and illegal drugs. In: Diagnosis and treatment of ADHD (Jensen P, Cooper J, eds), New York: American Medical Association.

McNamara CG, Davidson ES, Schenk S (1993) A comparison of the motor-activating effects of acute and chronic exposure to amphetamine and methylphenidate. Pharmacol Biochem Behav 45:729-732.

Mehta MA, Owen AM, Sahakian BJ, Mavaddat N, Pickard JD, Robbins TW (2000) Methylphenidate enhances working memory by modulating discrete frontal and parietal lobe regions in the human brain. J Neurosci 20:RC65.

Michelson D, Faries D, Wernicke J, Kelsey D, Kendrick K, Sallee FR, Spencer T, Atomoxetine ADHDSG (2001) Atomoxetine in the treatment of children and adolescents with attention-deficit/hyperactivity disorder: a randomized, placebo-controlled, dose-response study. Pediatrics 108:NIL33-NIL41.

Moll GH, Heinrich H, Trott GE, Wirth S, Rothenberger A (2000) Deficient intracortical inhibition in drug-naive children with attentiondeficit hyperactivity disorder is enhanced by methylphenidate. Neurosci Lett 284:121-125.

Mordenti J (1986) Man versus beast: pharmacokinetic scaling in mammals. J Pharmacol Sci 75:1028-1040.

National Institutes of Health Consensus Development Conference Statement (2000) Diagnosis and treatment of attention-deficit/hyperactivity disorder (ADHD). J Am Acad Child Adolesc Psychiatry 39:182-193.

Patrick KS, Markowitz JS (1997) Pharmacology of methylphenidate, amphetamine enantiomers and pemoline in attention-deficit hyperactivity disorder. Hum Psychopharmacol 12:527-546.

Patrick KS, Ellington KR, Breese GR (1984) Distribution of methylphenidate and $p$-hydroxymethylphenidate in rats. J Pharmacol Exp Ther 231:61-65.

Paulson PE, Robinson TE (1995) Amphetamine-induced timedependent sensitization of dopamine neurotransmission in the dorsal and ventral striatum: a microdialysis study in behaving rats. Synapse 19:56-65.

Pierce RC, Kalivas PW (1997) A circuitry model of the expression of behavioral sensitization to amphetamine-like psychostimulants. Brain Res Rev 25:192-216.

Robbins TW (2000) Chemical neuromodulation of frontal-executive functions in humans and other animals. Exp Brain Res 133:130-138.

Robinson TE, Becker JB (1986) Enduring changes in brain and behavior produced by chronic amphetamine administration: a review and evaluation of animal models of amphetamine psychosis. Brain Res Rev 11:157-198.

Robinson TE, Berridge KC (1993) The neural basis of drug craving: an incentive-sensitization theory of addiction. Brain Res Rev 18:247-291.

Robinson TE, Whishaw IQ (1988) Normalization of extracellular dopamine in striatum following recovery from a partial unilateral 6-OHDA lesion of the substantia nigra: a microdialysis study in freely moving rats. Brain Res 450:209-224.

Safer DJ, Allen RP (1989) Absence of tolerance to the behavioral effects of methylphenidate in hyperactive and inattentive children. J Pediat 115:1003-1008.

Sagvolden T (2001) The spontaneously hypertensive rat as a model for ADHD. In: Stimulant drugs and ADHD: basic and clinical neuroscience (Solanto MV, Arnsten AFT, Castellanos FX, eds), pp 221-237. New York: Oxford UP.

Salamone JD, Cousins MS, Snyder BJ (1997) Behavioral functions of nucleus accumbens dopamine: empirical and conceptual problems with the anhedonia hypothesis. Neurosci Biobehav Rev 21:341-359.

Sax KW, Strakowski SM (1998) Enhanced behavioral response to repeated D-amphetamine and personality traits in humans. Biol Psychiatry 44:1192-1195.

Scahill L, Chappell PB, Kim YS, Schultz RT, Katsovich L, Shepherd E, Arnsten AFT, Cohen DJ, Leckman JF (2001) A placebo-controlled study of guanfacine in the treatment of children with tic disorders and attention deficit hyperactivity disorder. Am J Psychiatry 158:1067-1074.

Schenk S, Davidson E (1998) Stimulant pre-exposure sensitizes rats and humans to the rewarding effects of cocaine. NIDA Res Monograph 169:56-82.

Segal DS, Kuczenski R (1987) Individual differences in responsiveness to single and repeated amphetamine administration: behavioral characteristics and neurochemical correlates. J Pharmacol Exp Ther 242:917-926.

Segal DS, Kuczenski R (1994) Behavioral pharmacology of amphetamine. In: Amphetamine and its analogues: psychopharmacology, toxicology and abuse (Cho AK, Segal DS, eds), pp 115-150. San Diego: Academic.

Sesack SR, Hawrylak VA, Matus C, Guido MA, Levey AI (1998) Dopamine axon varicosities in the prelimbic division of the rat prefrontal cortex exhibit sparse immunoreactivity for the dopamine transporter. J Neurosci 18:2697-2708.

Shaywitz SE, Hunt RD, Jatlow P, Cohen DJ, Young JG, Pierce RN, Anderson GM, Shaywitz BA (1982) Psychopharmacology of attention deficit disorder: pharmacokinetic, neuroendocrine, and behavioral measures following acute and chronic treatment with methylphenidate. Pediatrics 69:688-694.

Solanto MV, Arnsten AFT, Castellanos FX (2001) The neuroscience of stimulant drugs in ADHD. In: Stimulant drugs and ADHD: basic and clinical neuroscience (Solanto MV, Arnsten AFT, Castellanos FX, eds), pp 355-379. New York: Oxford UP.

Sripada S, Gaytan O, Al-Rahim S, Swann A, Dafny N (1998) Doserelated effects of MK-801 on acute and chronic methylphenidate administration. Brain Res 814:78-85.

Strakowski SM, Sax KW (1998) Progressive behavioral response to repeated D-amphetamine challenge: further evidence for sensitization in humans. Biol Psychiatry 44:1171-1177.

Strakowski SM, Sax KW, Rosenberg HL, DelBello MP, Adler CM (2001) Human response to repeated low-dose D-amphetamine: evidence for behavioral enhancement and tolerance. Neuropsychopharmacology 25:548-554.

Swanson JM, Volkow ND (2002) Pharmacokinetic and pharmacodynamic properties of stimulants: implications for the design of new treatments for ADHD. Behav Brain Res 130:73-78.

Swanson JM, Gupta S, Guinta D, Flynn D, Agler D, Lerner M, Williams L, Shoulson I, Wigal S (1999) Acute tolerance to methylphenidate in the treatment of attention deficit hyperactivity disorder in children. Clin Pharmacol Ther 66:295-305.

Szabo ST, Blier P (2001) Effect of the selective noradrenergic reuptake inhibitor reboxetine on the firing activity of noradrenaline and serotonin neurons. Eur J Neurosci 13:2077-2087.

Tanda G, Pontieri FE, Frau R, Di Chiara G (1997) Contribution of blockade of the noradrenaline carrier to the increase of extracellular dopamine in the rat prefrontal cortex by amphetamine and cocaine. Eur J Neurosci 9:2077-2085.

Taylor FB, Russo J (2001) Comparing guanfacine and dextroamphetamine for the treatment of adult attention-deficit/hyperactivity disorder. J Clin Psychopharmacol 21:223-228.

Taylor JR, Jentsch JD (2001) Stimulant effects on striatal and cortical dopamine systems involved in reward-related behavior and impulsivity: implications for ADHD. In: Stimulant drugs and ADHD: basic and clinical neuroscience (Solanto MV, Arnsten AFT, Castellanos FX, eds), pp 104-133. New York: Oxford UP.

Thai DL, Yurasits LN, Rudolph GR, Perel JM (1999) Comparative pharmacokinetics and tissue distribution of the $d$-enantiomers of parasubstituted methylphenidate analogs. Drug Metab Dis 27:645-650.

Vanderschuren LJMJ, Kalivas PW (2000) Alterations in dopaminergic and glutamatergic transmission in the induction and expression of behavioral sensitization: a critical review of preclinical studies. Psychopharmacology 151:99-120. 
Vitiello B, Severe JB, Greenhill LL, Arnold E, Abikoff H, Bukstein O, Elliott GR, Hechtman L, Jensen PS, Hinshaw S, March JS, Newcorn JH, Swanson JM, Cantwell DP (2001) Methylphenidate dosage for children with ADHD over time under controlled conditions: lessons from the MTA. J Am Acad Child Adolesc Psychiatry 40:188-196.

Volkow ND, Wang GJ, Fowler JS, Gatley SJ, Logan J, Ding YS, Hitzemann R, Pappas N (1998) Dopamine transporter occupancies in the human brain induced by therapeutic doses of oral methylphenidate. Am J Psychiatry 155:1325-1331.

Volkow ND, Wang GJ, Fowler JS, Logan J, Gerasimov M, Maynard L, Ding YS, Gatley SJ, Gifford A, Franceschi D (2001) Therapeutic doses of oral methylphenidate significantly increase extracellular dopamine in the human brain. J Neurosci 21:NIL1-NIL5.

Wargin W, Kilts PC, Gualtieri CT, Ellington KR, Mueller RA, Kraemer
G, Breese GR (1983) Pharmacokinetics of methylphenidate in man, rat and monkey. J Pharmacol Exp Ther 226:382-386.

Wayment HK, Schenk JO, Sorg BA (2001) Characterization of extracellular dopamine clearance in the medial prefrontal cortex: role of monoamine uptake and monoamine oxidase inhibition. J Neurosci 21:35-44.

White FJ (1996) Synaptic regulation of mesocorticolimbic dopamine neurons. Annu Rev Neurosci 19:405-436.

White FJ, Kalivas PW (1998) Neuroadaptations involved in amphetamine and cocaine addiction. Drug Alcohol Depend 51:141-153.

Wigal T, Swanson JM, Regino R, Lerner MA, Soliman I, Steinhoff K, Gurbani S, Wigal SB (1999) Stimulant medications for the treatment of ADHD: efficacy and limitations. Ment Retard Dev Disabil Res Rev $5: 215-224$. 